\title{
Do paralympic track and field athletes have low energy availlability?
}

\section{Os atletas do atletismo paralímpico tem baixa energia disponível?}

Daniel Paduan Joaquim ${ }^{1,2}$

Claudia Ridel Juzwiak ${ }^{3}$

Ciro Winckler ${ }^{2,3,4}$

Abstract - One of the greatest challenges when working with athletes is to achieve the energy demands for physiological processes and exercise expenditure. The aim of this study was to assess the energy availability (EA) of Paralympic track and field athletes (sprinters). Seventeen athletes (9 male and 8 female) with visual impairment (VI, $n=10)$, cerebral palsy $(C P, n=4)$ and limb deficiency $(L D, n=3)$ were assessed for energy intake (EI) (4-day food photographic record), energy expenditure with exercise (EEex) (motion sensor), and body composition (skinfolds method). Energy availability was estimated using the equation: $\mathrm{EA}=\left(\mathrm{EI}_{\mathrm{kcal}}-\mathrm{EEex}_{\mathrm{kca}}\right) /$ fat-free mass $(\mathrm{FFM}) /$ day, and values $\leq 30 \mathrm{kcal} /$ $\mathrm{kgFFM} /$ day were considered as low energy availability (LEA). EEex varied from 130 to $477 \mathrm{kcal} / \mathrm{h}$ and athletes trained in average for 3.2 hours per day. Mean EA for VI, LD and CP were 36 (2.19), 37 (1.90) and 38 (3.38) kcal/kgFFM/day, respectively. Most (82.3\%) participants presented EA below $\geq 45 \mathrm{kcal} / \mathrm{kgFFM} /$ day, throughout the days, which are the recommended values for athletes without disability. Athletes should be encouraged to consume adequate EA to avoid consequences related to low energy availability. There is need of further research to identify cut-off values adequate for this population.

Key words: Athletes; Energy expenditure; Energy intake; Sports for persons with disabilities.

Resumo - Um dos maiores desafios ao trabalhar com atletas é alcançar as demandas de energia para os processos fisiológicos e despesas com exercícios. O objetivo deste estudo foi avaliar a disponibilidade de energia (EA) dos atletas paralimpico de atletismo (velocistas). Dezessete atletas (9 homens e 8 mulheres) com deficiência visual ( $V I, n=10)$, paralisia cerebral $(C P, n=4)$ e deficiência motora ( $L D, n=3$ ) foram avaliados quanto à ingestão de energia (EI) (4 dias de registro fotográfico dos alimentos), gasto de energia com exercicio (EEex) (sensor de movimento) e composição corporal (método de dobras cutâneas). A disponibilidade de energia foi estimada usando a equação: $E A$ = (EIkcal - EEexkcal) / massa livre de gordura $(F F M) /$ dia e, os valores $\leq 30 \mathrm{kcal} / \mathrm{kgFFM} /$ dia foram considerados como baixa disponibilidade de energia (LEA). $O$ EEex variou de 130 a $477 \mathrm{kcal} / \mathrm{h}$ e os atletas treinaram em média por 3,2 horas por dia. A EA média para VI, LD e CP foi 36 (2,19), $37(1,90)$ e 38 (3,38) kcal/kgFFM/dia, respectivamente. A maioria (82,3\%) participantes apresentaram EA abaixo de $\geq 45 \mathrm{kcal} / \mathrm{kgFFM} /$ dia, ao longo dos dias, que são os valores recomendados para atletas sem deficiência. Os atletas devem ser encorajados a consumir EA adequada para evitar conseqüencias relacionadas a baixa disponibilidade de energia. Há necessidade de pesquisas adicionais para identificar valores de corte adequados para essa população.

Palavras-chave: Atleta; Esportes para pessoas com deficiência; Gasto energético; Ingestão de energia.

1 Universidade Federal de São Paulo. Campus Baixada Santista. Programa de Pós-graduação Interdisciplinar em Ciências da Saúde. Santos, SP. Brasil.

2 Comitê Paralímpico Brasileiro. São Paulo, SP. Brasil.

3 Universidade Federal de São Paulo. Departamento de Ciências do Movimento Humano. São Paulo, SP. Brasil.

4 Academia Paralímpica Brasileira. São Paulo, SP. Brasil.

Received: 26 October 2017 Accepted: 17 December 2017

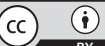

Licença Creative Commom 


\section{INTRODUCTION}

Athletes' energy requirements represent the sufficient quantity of energy to cover the everyday demands of exercise, in addition to maintenance of health ${ }^{1}$. Energy requirements are influenced by training periodization and the characteristics of daily training sessions, varying according to volume and intensity of exercise $e^{2}$. As consequences of an insufficient energy supply, physiological aspects such as basal metabolic rate, menstrual function, bone health, protein synthesis, immunity and cardiovascular health can be negatively affected, causing a consequent decrease in athletic performance ${ }^{3}$.

Energy Availability (EA) has been suggested as the best strategy to identify if the energy consumed supplies enough energy for the remaining physiological processes, after the energy expenditure with exercise (EEex) is considered, and adjusted to fat free mass $(\mathrm{FFM})^{2,3,4}$.

Low Energy Availability (LEA) has been implicated in two syndromes related to athletes: the Female Athlete Triad (FAT) and the Relative Energy Deficiency in Sports (RED-S). FAT involves three inter-related components: energy availability, menstrual status and bone health. The most severe presentation of FAT is characterized by LEA with or without an eating disorder (ED), functional hypothalamic amenorrhea and low bone mineral density 3,5 . RED-S proposes a wider spectrum of symptoms, involving many body systems, resulting in short-term and long-term compromise of optimal health and performance. Athletes who suffer from long-term LEA may develop nutrient deficiencies, chronic fatigue and increased risk of infections and illnesses. Physiological complications involve the cardiovascular, gastrointestinal, endocrine, reproductive, skeletal, renal and central nervous systems ${ }^{2,3}$.

Studies ${ }^{1,3,6}$ assessed different components associated with the risk of FAT development, but few evaluated EA itself. Blauwet et al. ${ }^{7}$ draw attention to the lack of knowledge on the prevalence of low energy availability and components of FAT or REDs in athletes with disabilities. However, it is believed that due to the characteristics of each deficiency, there may be changes in energy requirements, bone heath and menstrual dysfunction, which differ from able-bodied athletes ${ }^{7,8}$. Considering the lack of knowledge in this area, the aim of this study was to evaluate EA in Paralympic athletes of the Brazilian national track \& field team.

\section{METHODOLOGICAL PROCEDURES}

The Ethics Committee of the Federal University of São Paulo approved this study under appraisal \#921.384/2014. All athletes were briefed on the objectives and procedure and signed an informed and written consent.

\section{Subjects}

Seventeen Paralympic track and field athletes (9 male and 8 female) of functional classes visual impairment (VI; $n=10)$, cerebral palsy $(C P ; n=4)$ 
and limb deficiency (LD; $n=3$ ), all sprinters with international experience, participated in this study. The LD athletes presented upper limb amputation (one bilateral hand amputation, one forearm level amputation and one hand amputation). In all cases, amputations did not represent more than $2.5 \%$ loss of body mass, according Osterkamp 9 . Two CP presented spasticity and two athetoid CP, with hemiplegia on the left side of the body. Eight VI athletes were blind and two had low vision.

\section{Procedures}

Data were collected during four consecutive days, during one of the Evaluation Weeks (EW) within the annual evaluation cycle of the High Performance Program of the Brazilian Paralympic Committee, conducted between the pre-competitive/competitive training periods. The program proposes one week (five consecutive days) of physical evaluation every three months along the year. Athletes were housed in a hotel, where they received three meals/days (self-service buffet) and snack-kits. The EW has an extensive routine of physical tests/assessments with the professional team (dietitian, physician, psychologist and physiotherapist) interspersed with training periods.

Athletes had their body mass/composition assed in the first and last day of the EW and only athletes who were not controlling body mass/ composition participated in the study.

\section{Dietary energy intake}

All information on food/beverage/supplement consumed or food remains was recorded on a digital worksheet and a photographic record was carried out by one of the researchers (DPJ) using a high-resolution digital camera. At the end of the day, photographs were loaded onto the researcher's computer. Athletes were instructed to inform if they had seconds, snacks, and all extra foods or supplements consumed along the day (e.g. candies, sport drinks, etc.).

The meals were held in the restaurant where the athletes ate their meals. The self-service buffet provided for breakfast: breads (whole and white), ham, cheese (mozzarella and parmesan), natural fruit juice, milk and fruits (3 types); for lunch and dinner: vegetables (six types: two raw leaves, two raw vegetables and one cooked or steamed vegetable), main dishes (white and brown rice, beans, two meat options, and pasta or tubers cooked as side dishes), and a dessert buffet (two types of sweets and two types of fruit). Athletes could serve themselves of any type of preparation at will. A standardized snack-kit composed by 1 sandwich (whole grain bread with 1 slice of yellow cheese and 1 slice of lean ham), 2 fruits and $200 \mathrm{~mL}$ of processed fruit juice) was available to athletes in the intervals between meals and were consumed pre, during or post training.

Athletes were instructed to choose their usual foods and quantities. VI athletes had their meals served by the athlete-guides, as requested. Consumed amounts were converted to grams according to comparison 
of consumption with standard photographic portions. EI (kcal/day) were calculated using the software Avanutri ${ }^{\oplus}$ version 4.0

\section{Anthropometric and Body Composition Assessment}

Body mass $(\mathrm{kg})$ was assessed using an electronic scale $(0.1 \mathrm{~kg}$ accuracy) and height $(\mathrm{cm})$ using a stadiometer $(0.1 \mathrm{~cm}$ accuracy). All athletes were assessed standing, with both feet together and head placed in Frankfort plane. Body skinfolds were assessed using Lange ${ }^{\circledast}$ skinfold callipers (accuracy of $1 \mathrm{~mm}$ and constant pressure of $10 \mathrm{~g} / \mathrm{mm}^{2}$ ), on the right side of the body, with the exception of athletes with CP and LD, who were measured on the non-affected side.

To control for intra-evaluator variability, the skinfolds measurements were obtained from the mean of three repeated measurements, by the same anthropometrist who presents typical error measurement of $2.24 \%$.

Skinfolds (triceps, subscapular, biceps, iliac crest, abdominal, thigh and calf) were measured according to the procedures proposed by the International Society for the Advancement of Kinanthropometry ${ }^{10}$, while the midaxillary and chest skinfolds according to Lohman ${ }^{11}$. Body density was estimated by Jackson \& Pollock ${ }^{12,13}$ equations, for men and women, respectively, and all converted to body fat percentage by Siri's equation ${ }^{14}$.

\section{Energy Expenditure with Exercise}

The EEex assessment was conducted using the Actical ${ }^{\oplus}$ (Mini-Mitter Co., Bend, OR, USA) multidirectional accelerometer which monitors the occurrence of movement through acceleration. The device measures acceleration from 0.005 to $2.0 \mathrm{G}$, and has a frequency range between 0.5 to $3.0 \mathrm{~Hz}$, memory capacity of $32 \mathrm{MB}$, dimensions of $29 \mathrm{~mm} \times 37 \mathrm{~mm} \times 11 \mathrm{~mm}$ and weighs $22 \mathrm{~g}$. Athlete's height, body mass, gender and age were registered in the Actical ${ }^{\oplus}$. During exercise, movement information was stored every 15 seconds and converted into 1-minute intervals for data analysis. The device was attached by an elastic band to the athlete's body, on the anterior axillary line, on the iliac crest, on the right side of the body, during the four of the evaluation. Athletes were instructed to use the device throughout the sports activities, being placed on Monday and removed on Friday. The devices were collected on the fifth day of the EW, after breakfast.

Training was composed of warm-up exercise (cardiovascular and 10 types of educational running), mobility activities, sprinter running $(9.8 \mathrm{~m} / \mathrm{s})$, and strength exercises, totalling 180 minutes of exercise per day (1 or 2 session).

\section{Energy Availability}

EA was calculated using the equation: $\left[\mathrm{EA}=\mathrm{EI}_{(\mathrm{kcal})}-\mathrm{EEex}_{(\mathrm{kcal})} / \mathrm{FFM}\right.$ $(\mathrm{kg})]$. EA cut-off values were: $\geq 45 \mathrm{kcal} / \mathrm{kgFFM} /$ day - adequate EA; between 30 to $45 \mathrm{kcal} / \mathrm{kgFFM} /$ day - reduced EA and values $\leq 30 \mathrm{kcal} /$ $\mathrm{kgFFM} /$ day - LEA ${ }^{2,3,4}$.

\section{Statistical Analysis}

Data were processed using SPSS $^{\circledast}$ software version 20.0. Data descriptive 
analysis of is presented as mean and standard-deviation. The normality of the sample was tested by Shapiro-Wilk. Paired t tests were used to determine differences between genders. To compare the functional classes in relation to the study variables, the model of analysis of variance with a fixed factor was used, being considered significant differences when $p \leq 0.05$. To verify the difference between the days, the repeated measures of Variance Analysis Model, and the Bonferroni multiple comparisons method was used. Significance was established when $\mathrm{p} \leq 0.05$. In addition, we calculated the effect-size $(F)$ and confidence interval $(95 \% \mathrm{CI})$.

\section{RESULTS}

The anthropometric, body composition and training characteristics of the athletes are summarized in Table 1, according to the functional classification.

Table 1. Characterization of the sample according to the functional classification

\begin{tabular}{lccc}
\hline & VI & LD & CP \\
\hline & $(\mathrm{n}=10)$ & $(\mathrm{n}=03)$ & $(\mathrm{n}=04)$ \\
\hline Mean (SD) & Mean (SD) & Mean (SD) \\
\hline Hge (years) & $26(6.17)$ & $27(8.50)$ & $24(7.54)$ \\
Bour of training (h/day) & $3.0(0.57)$ & $3.6(1.20)$ & $3.4(0.48)$ \\
Height $(\mathrm{m})$ & $62.0(10.53)$ & $59.9(9.66)$ & $63.9(11.10)$ \\
Fat Free Mass $(\mathrm{kg})$ & $1.68(0.09)$ & $1.69(0.05)$ & $1.75(0.12)$ \\
Sum Skinfolds $(\mathrm{mm})^{\mathrm{a}}$ & $54.4(11.38)$ & $54.7(8.22)$ & $59.1(11.64)$ \\
\hline
\end{tabular}

$\mathrm{SD}=$ standard deviation; $\mathrm{VI}=$ visual impairment; $\mathrm{LD}=$ =limb deficiency; $\mathrm{CP}=$ cerebral palsy; $\mathrm{VI}$ functional class: (11, 12 e 13); CP functional class: (36 and 38); LD functional class: (46 and 47); ${ }^{\text {S }}$ um Skinfolds $(\mathrm{mm})$ : triceps, subscapular, biceps, midaxillary, chest, iliac crest, abdominal, thigh and calf.

Table 2 shows the EI (kcal/day), EEex (kcal/hour), and EA (kcal/ $\mathrm{kgFFM} /$ day) according to athletes' functional classification. No difference was found between groups evaluated for EI $(p=0.281)$, EEex $(p=0.773)$, and $\mathrm{EA}(\mathrm{p}=0.485)$.

Table 2. Energy Intake (EI), Energy Expenditure with e Exercise (EEex) and Energy Availability (EA), based on four-days data collection, according to the functional classification

\begin{tabular}{lcccc}
\hline & & $\begin{array}{c}\text { El } \\
(\text { kcal/day })^{\mathrm{a}}\end{array}$ & ${\text { EEex }(\text { kcal/hour })^{\mathrm{b}}}$ & $\begin{array}{c}\text { EA } \\
(\mathrm{kcal} / \mathrm{kgFFM} / \text { day })^{\mathrm{c}}\end{array}$ \\
\hline $\mathrm{VI}$ & $(\mathrm{n}=10)$ & $2262(483.15)$ & $314(111.85)$ & $36.3(6.99)$ \\
LD & $(\mathrm{n}=3)$ & $2359(466.13)$ & $324(144.28)$ & $37.2(3.32)$ \\
CP & $(n=4)$ & $2518(192.52)$ & $293(71.92)$ & $38.6(6.46)$ \\
\hline
\end{tabular}

$\mathrm{SD}=$ standard deviation; $\mathrm{VI}=\mathrm{visual}$ impairment; $\mathrm{LD}=\operatorname{limb}$ deficiency; $\mathrm{CP}=$ cerebral palsy; ${ }^{\mathrm{a}} \mathrm{El}=\mathrm{Energy}$

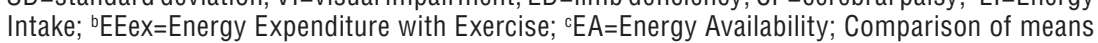
between groups for the $\mathrm{El}(\mathrm{p}=0.281)$; for the $\mathrm{EEex}(p=0.773)$ and for the $E A(p=0.485)$; Comparison of means between male and female $(p=0.845)$. 
There was no difference $(p=0.845)$ in EA between male and female athletes. The values of EI (kcal/day) and EEex (kcal/hour) were lower among female athletes than among male athletes in all functional classes. No difference was found in EI ( $k$ cal/day) between days ( $\mathrm{p}=0.791)$ according to functional classification and between groups $(\mathrm{p}=0.541)$.

Table 3 shows EA values ( $\mathrm{kcal} / \mathrm{kgFFM} / \mathrm{day}$ ) between evaluated days. No difference was found ( $\mathrm{p}=0.524)$ between the evaluated days and between the groups $(\mathrm{p}=0.761)$.

Table 3. Energy Availability (kcal/kgFFM/day) according to functional classification and gender

\begin{tabular}{|c|c|c|c|c|c|}
\hline & & Day 1 & Day 2 & Day 3 & Day 4 \\
\hline \multirow{11}{*}{ VI } & \multirow{4}{*}{ Male $(n=4)$} & 35 & 30 & 34 & 35 \\
\hline & & 39 & 52 & 45 & 52 \\
\hline & & 31 & 42 & 30 & 36 \\
\hline & & 32 & 25 & 27 & 38 \\
\hline & \multirow{6}{*}{ Female $(n=6)$} & 40 & 39 & 46 & 43 \\
\hline & & 56 & 67 & 33 & 38 \\
\hline & & 25 & 30 & 39 & 34 \\
\hline & & 27 & 34 & 30 & 35 \\
\hline & & 40 & 34 & 35 & 23 \\
\hline & & 33 & 29 & 25 & 35 \\
\hline & Total $(n=10)^{a}$ & $36(8.83)$ & $38(12.66)$ & $34(7.02)$ & $37(7.47)$ \\
\hline \multirow{4}{*}{ LD } & \multirow{2}{*}{ Male $(n=2)$} & 36 & 31 & 27 & 46 \\
\hline & & 36 & 47 & 35 & 46 \\
\hline & Female $(n=1)$ & 34 & 29 & 48 & 30 \\
\hline & Total $(n=3)^{\mathrm{a}}$ & $35(1.16)$ & 35 (9.94) & 37 (10.5) & $41(9.23)$ \\
\hline \multirow{5}{*}{$\mathrm{CP}$} & \multirow{3}{*}{ Male $(n=3)$} & 34 & 34 & 33 & 43 \\
\hline & & 41 & 36 & 34 & 39 \\
\hline & & 29 & 29 & 37 & 36 \\
\hline & Female $(n=1)$ & 46 & 57 & 43 & 46 \\
\hline & Total $(n=4)^{\mathrm{a}}$ & 37 (7.15) & 39 (12.3) & $37(4.10)$ & $41(4.55)$ \\
\hline
\end{tabular}

${ }^{a}$ Data presented as mean (standard deviation); VI=visual impairment; $L D=\operatorname{limb}$ deficiency; $\mathrm{CP}=$ cerebral palsy; Comparison of EA ( $\mathrm{kcal} / \mathrm{kgFFMday})$ between days $(p=0.524)$; Comparison of EA ( $\mathrm{kcal} / \mathrm{kgFFM} /$ day) between groups $(p=0.761)$.

Four parathletes presented adequate EA in at least two days. A reduced EA was observed in 70.5\%, 52.9\%, 91.6\% and 70.5\% for days 1, 2, 3 and 4, respectively. LEA was present for $17.6 \%, 33.3 \%, 33.3 \%$ and $8.3 \%$ of athletes for days 1, 2, 3 and 4, respectively. No athlete consumed EA below $30 \mathrm{kcal} / \mathrm{kgFFM} /$ day for more than 2 days. 


\section{DISCUSSION}

This is a pioneer study in the assessment of EA in a Paralympic track \& field population. EA assessment is particularly challenging when working with parathletes, as all the methods for estimating the EA components require maximal care to be as accurate as possible, and the available possibilities have limitations for the studied population, depending on the functional classification. For example, FFM may be altered as a result of the deficiency, such as in the case of LD and CP, compromising the determination of FFM and, consequently, EA 7 .

Van de Vliet et al. ${ }^{15}$ suggest the use of the sum of skinfolds for the longitudinal monitoring of athletes with disabilities, avoiding the use of non-specific predictive equations for this population. However, the FFM $(\mathrm{kg})$ estimation is fundamental for the determination of EA. The use of predictive equations such as Jackson and Pollock' ${ }^{12,13}$, even though nonspecific for this population has been used in other studies ${ }^{16,17}$. Furthermore, we adopted Jackson and Pollock equations considering that the assessed athletes were athletes VI, who are physiologically similar to athletes without disability, only LD athletes whose deficiency represented less than 2.5\% of body mass, and only $\mathrm{CP}$ athletes, who belong to functional classes with low body commitment. The more physiologically closer to an able-body condition, the less critical is the use of these equations ${ }^{8}$.

There is a fair amount of information on EEex in athletes without disability, however, for parathletes, there is scarce information because of the difficulty in accurately determining EEex. Multidirectional accelerometers are being used to assess EEex, which can detect movements in more than one plane and, therefore, and are considered as more accurate ${ }^{18}$, and may be a good alternative for this population ${ }^{8}$, interfering minimally in the athletes' routine training. However, there may be an underestimation of the exercise according to the positioning of the instrument in the body, as well as the type of exercise performed ${ }^{19}$. Esliger and Tremblay ${ }^{20}$ demonstrated a greater reliability $(\mathrm{CV}=0.5 \%)$ intra-instrument when compared the Acti$\mathrm{cal}^{\circledast}$ to other accelerometers in population without disability. Brazeau et al. ${ }^{21}$, investigated the validity and reliability of Actical ${ }^{\oplus}$ to evaluate EEex, compared to the double-labelled water technique, and results showed that the Actical ${ }^{\oplus}$ is reliable for the evaluation of EEex, with little imprecision, underestimating EEex to $-244 \mathrm{kcal} / \mathrm{d}$. However, there is no validity and reliability information on Paralympic athletes. No studies with a similar sample to our study were found, and the majority of studies on EEex of parathletes are conducted with subjects with spinal cord injury. Even among athletes without disability, there are few studies on sprinters. Therefore, our results should be considered with caution.

All methods to assess EI may present a bias due to memory, level of participation of responder, underreporting (intentional or not), and it is not different with para athletes. In this study, we chose to collect food data using a photographic record aiming to obtain more accurate information ${ }^{22,23}$ 
and reducing the information bias on food consumption. Furthermore, for VI athletes, and some LD athletes, it was more comfortable to have the investigator taking the pictures than asking them to register what they ate. Food provided during the EW respect the typical Brazilian every-day food habits, therefore, athletes can eat what they are used to. Nevertheless, athletes encounter a greater variety of foods and that can lead to different food choices and to a greater amount ingested.

But the greatest challenge in this study is the very use of the cut-off values of EA for the Paralympic population, which were determined for athletes without disability. Paralympic athletes (such as athletes with $\mathrm{CP}$, LD) may have a lower body muscle mass due to contraction disorders, as well as a different energy demand due to the deficiency ${ }^{8}$. In addition, these cut-off values have been proposed mainly for female athletes. Therefore, we can only infer that the values we observed represent a reduced EA in some of these athletes. On the other hand, athletes with VI do not have physiologic differences from athletes without disability; therefore, we suggest that the EA cut-off values can be appropriate for this specific group.

Although all the difficulties and limitations in assessing EA components in this group of athletes, some specific conditions during assessment of EEex and EI components in this study should be taken into consideration. During the EW, the food provided represents the typical Brazilian dishes. However, it is generally more varied and abundant than in the athletes' households, which can lead to different food choices As far as training is concerned, their individualized training schedule is respected, but adapted to allow them to undergo other activities. Training was different from the athletes' usual training, due to lower intensity and/ or duration of the activities, similar to the moment of the competition, since the objective of the period was the physical evaluation of the athletes. Considering their training schedule (monitored by trainers), the specific training sessions (speed race) are short, but the recovery periods between the specific exercises are long.

Considering that EEex was lower and available food more abundant than usual we hypothesized that EA would be adequate. However, for all groups mean EA was below $45 \mathrm{kcal} / \mathrm{kgFFM} /$ day. Furthermore, LEA was detected for at least one day in 8 athletes, evidencing the need of constant attention to the adjustment of EI to EEex of these athletes. In studies with cyclists without disability ${ }^{24}$ and soccer players ${ }^{6}$ LEA was identified in different moments of the periodization (pre-season, competition and postseason). Viner et al. ${ }^{24}$ associated LEA to the conscious practice of cyclists to restrict energy consumption (kcal/day) to reduce/maintain body mass and body fat percentage, which is also common practice among runners ${ }^{25}$.

In the present study, the lower EI (kcal/day) observed in some days, may be explained due to the difference in taste and variety of preparations. It is important to highlight that athlete-guides have an important role in athletes with VI's food choices, since they assist them in assembling and portioning the meals. These are subject to the interpretation of the athlete- 
guide, since the quantities requested by the athlete VI may be inaccurate. This may have influenced EI and also the EA values found for these athletes. We found only one study which assessed track and field female athletes $(\mathrm{n}=25$, including sprinters) which observed that $52 \%$ of the athletes were at LEA, 40\% had amenorrhea and 32\% had a history of stress fractures and consequently the risk of RED-S ${ }^{26}$. No study was found evaluating Paralympic athletes.

Although we cannot affirm that all athletes who presented EA below $30 \mathrm{kcal} / \mathrm{kgFFM} /$ day in this study have LEA, as the cut-off values were not determined for the Paralympic population, we should be aware of them and aim to manage EI and EEex constantly, following changes in the periodization and training dynamics, FFM adjustments, and changes in diet, since this decrease may adversely affect health and performance, when $\mathrm{EI}$ (kcal/day) is not being adjusted to EEex.

We highlight that the EA values in our study refer to a specific assessment period, and cannot be extrapolated to athletes' usual training. Another aspect to be considered is the size of the sample, as they represent the elite of Paralympic track and field athletes, and there is still the subdivision according to functional classification and sex, which may have influenced the power to detect differences between groups or between days for assessment of EA.

\section{CONCLUSION}

Like any other athlete, Paralympic athletes who have high exercise EEex and restrict $\mathrm{EI}$ or are not able to adjust their daily EI do changes in EEex volumes should be followed-up carefully because they are at risk of developing LEA and its consequences. Although no cut-off values to determine LEA in Paralympic athletes have been proposed, we hope our results arouse awareness and motivate the development of studies to improve knowledge about EA and its components in this population, in order to avoid implications related to FAT and RED-S.

\section{Acknowledgements}

All of the authors are grateful to the Brazilian Paralympic Committee (CPB), Brazilian Paralympic Academy (APB) and Conselho Nacional de Desenvolvimento Cientifico e Tecnológico (CNPq).

\section{REFERENCE}

1. Woodruff SJ, Meloche RD. Energy availability of female varsity volleyball players. Int J Sport Nutr Exerc Metab 2013;23(1):24-30.

2. Thomas DT, Erdman KA, Burke LM. Nutrition and athletic performance. J Acad Nutr Diet 2016;116(3):501-28.

3. Mountjoy M, Sundgot-Borgen J, Burke L, Carter S, Constantini N, Lebrun C, et al. The IOC consensus statement: beyond the Female Athlete Triad - Relative Energy Deficiency in Sport (RED-S). Br J Sports Med 2014;48(7):491-7. 
4. Loucks AB, Kiens B, Wright HH. Energy availability in athletes. J Sports Sci 2011;29(Suppl 1):S7-15.

5. De Souza MJ, Nattiv A, Joy E, Misra M, Williams NI, Mallinson RJ, et al. 2014 Female Athlete Triad Coalition Consensus Statement on Treatment and Return to Play of the Female Athlete Triad: 1st International Conference held in San Francisco, California, May 2012 and 2nd International Conference held in Indianapolis, Indiana, May 2013. Br J Sports Med 2014;48(4):1-20.

6. Reed JL, Souza MJ, Williams NI. Changes in energy availability across the season in Division I female soccer players. J Sports Sci 2013;31(3):314-24.

7. Blauwet CA, Brook EM, Tenforde AS, Broad E, Hu CH, Abdu-Glass E, et al. Low energy availability, menstrual dysfunction, and low bone mineral density in individuals with a disability: implications for the para athlete population. Sports Med 2017;47(9):1697-708.

8. Broad E, Burke L. Principles of sport nutrition. In: Sport nutrition of paralympic athletes. Boca Raton, CRC Press; 2014. p. 23-65.

9. Osterkamp LK. Current perspective on assessment of human body proportions of relevance to amputees. J Am Diet Assoc 1995;95(2):215-8.

10. International Society for the Advancement of Kinanthropometry. International standards for anthropometric assessment. Ed. Australia, National Library of Australia, 2001.

11. Lohman TG. Skinfolds and body density and their relation to body fatness: a review. Hum Biol. 1981;53(2):181-225.

12. Jackson AS, Pollock ML. Generalized equations for predicting body density of men. Br J Nutr 1978;40(3):497-504.

13. Jackson AS, Pollock ML, Ward A. Generalized equations for predicting body density of women. Med Sci Sports Exerc 1980;12(3):175-81.

14. Siri WE. Body Composition from fluid spaces and density: analysis of methods. In: Techniques for measuring body composition. Washington, National Academy of Science; 1961. p. 223-241.

15. Van de Vliet P, Broad E, Strupler M. Nutrition, body composition and pharmacology In: The Paralympic Athlete. UK, Wiley-Blackwell; 2011. p.172-197.

16. Gomes AIS, Ribeiro BG, Soares EA. Nutritional characterization of elite amputee soccer players. Rev Bras Med Esporte 2006; 11(1):17-21.

17. Juzwiak CR, Winckler C, Joaquim DP, Silva A, Mello MT. Comparison of measured and predictive values of basal metabolic rate in brazilian paralympic Track and Field athletes. Int J Sport Nutr Exerc Metab 2016;26(4):330-7.

18. Heil DP. Predicting activity energy expenditure using the Actical ${ }^{\circledR}$ activity monitor. Res Q Exerc Sport 2006;77(1):64-80.

19. Aparicio-Ugarriza R, Mielgo-Ayuso J, Benito P, Pedrero-Chamizoo R, Ara I, Gonzalez-Gross M. Physical activity assessment in the general population; instrumental methods and new technologies. Nutr Hosp 2015;26(Suppl 3):219-26.

20. Esliger D, Tremblay M. Technical reliability assessment of three accelerometer models in a mechanical setup. Med Sci Sports Exerc 2006;38(12):2173-81.

21. Brazeau A, Beadoin N, Bélisle V, Messier V, Karelis A, Rabasa-Lhoret R. Validation and reliability of two activity monitor for energy expenditure assessment. J Sci Med Sport 2016;19(1):46-50.

22. Wang H, Kogashiwa M, Ohta S, Kira S. Validity and reliability of a dietary assessment method: The application of a digital camera with a mobile phone card attachment. J Nutr Sci Vitaminol 2002;48(6):498-504.

23. Williamson D, Allen H, Martin P, Alfonso A, Gerald B, Hunt A. Comparison of digital photography to weighed and visual estimation of portion sizes. J Am Diet Assoc 2003;103(9):1139-45.

24. Viner RT, Harris M, Berning JR, Meyer N. Energy availability and dietary patterns of adult male and female competitive cyclists with lower than expected bone mineral density. Int J Sport Nutr Exerc Metab 2015;25(6):594-602. 
25. Sundgot-Borgen J, Meyer NL, Lohman T, Ackland T, Maughan R, Stewart A, et al. How to minimize the health risks to athletes who compete in weight-sensitive sports review and position statement on behalf of the Ad Hoc Research Working Group on Body Composition, Health and Performance, under the auspices of the IOC Medical Commission. Br J Sports Med 2013;47(16):1012-22.

26. Day J, Wengreen H, Heath E, Brown K. Prevalence of low energy availability in collegiate female runners and implementation of nutrition education intervention. Sports Nutr Ther 2015;1(1):1-7.

\section{CORRESPONDING AUTHOR}

Daniel Paduan Joaquim Comitê Paralímpico Brasileiro. Rodovia dos Imigrantes - Vila Guarani - 04329000 - São Paulo, SP-Brasil.

Email: daniel_paduan@hotmail.com 